\title{
Esporte, gênero e ideologia: a (des)construção de Ronda Rousey no comercial \#PerfectNever ${ }^{1}$
} Tarcyanie Cajueiro Santos e Felipe Tavares Paes Lopes

\section{Resumo}

Neste trabalho, buscamos responder as questões: como as atletas do Ultimate Fighter Championship (UFC) são simbolicamente construídas por peças publicitárias? Em que medida e como essas construções se entrecruzam com relações de dominação de gênero em um esporte tradicionalmente considerado masculino? Analisamos e interpretamos o potencial ideológico e o contestatório dos sentidos mobilizados pelo comercial da Rebook \#PerfectNever, protagonizado pela ex-campeã de UFC Ronda Rousey. Para tanto, adotamos a metodologia da hermenêutica de profundidade, de Thompson. Concluímos que, do ponto de vista das relações de gênero, o comercial é potencialmente subversivo e, do ponto de vista das relações de classe, potencialmente ideológico.

\section{Palavras-Chave}

Esporte. Gênero. Ideologia. Publicidade.
Tarcyanie Cajueiro Santos I tarcyanie@terra.com.br Docente do Programa de Pós-Graduação em Comunicação e Cultura da Universidade de Sorocaba - UNISO, Brasil.

Felipe Tavares Paes Lopes | lopesftp@gmail.com Docente do Programa de Pós-Graduação em Comunicação e Cultura da Universidade de Sorocaba - UNISO, Brasil. Bolsista da Fundação de Amparo à Pesquisa do Estado de São Paulo.

\section{Introdução}

Este trabalho apresenta os resultados de uma pesquisa em desenvolvimento sobre esporte, gênero e ideologia, a partir principalmente das teorias de John B. Thompson e Gilles Lipovetsky. Mais exatamente, busca responder as seguintes questões: como as atletas do Ultimate Fighter Championship (UFC) são simbolicamente construídas por peças publicitárias? Em que medida e como essas construções se entrecruzam com relações de dominação de gênero em um esporte tradicionalmente considerado masculino? Tomando essas questões como ponto de partida, analisamos e interpretamos o potencial ideológico e o contestatório dos sentidos mobilizados pelo comercial da Rebook \#PerfectNever, protagonizado pela ex-campeã de UFC Ronda Rousey.

Ronda é uma das melhores atletas do campo dos esportes de combate, tendo sido a primeira medalhista de judô dos Estados Unidos em Jogos Olímpicos, conquistando a de bronze em Pequim, em 2008. A americana tornou-se uma celebridade ao conquistar o cinturão peso-galo do Strikerforce 
e foi a primeira detentora do Cinturão Peso Galo Feminino do UFC. Contratada para fazer parte do evento em 2012, perdeu sua invencibilidade apenas no final de 2015, para Holly Holm. Invicta no MMA e campeã de boxe, Holm derrubou Ronda no segundo round e foi para cima da adversária, acertando-lhe uma série de golpes, que fez o juiz paralisar a luta e decretar o seu fim.

Este evento foi o pano de fundo contra 0 qual o comercial \#PerfectNever foi veiculado. Para discuti-lo, optamos por organizar 0 artigo em quatro partes. Em um primeiro momento, descrevemos e analisamos o contexto sócio histórico de produção, transmissão e recepção do referido comercial, enfocando a história das Artes Marciais Mistas (MMA) e as relações de gênero nesse esporte - com especial atenção aos padrões socialmente construídos de beleza feminina. Em um segundo momento, apresentamos 0 conceito de ideologia utilizado. Em um terceiro momento, apresentamos nosso percurso metodológico.

Por fim, expomos a análise e interpretação do potencial ideológico e contestatório do comercial.

\section{História do UFC, relações de gênero e beleza feminina}

0 esporte moderno começou a se desenvolver na Grã-Bretanha a partir do século XVIII, quando o "[...] o esporte tornou-se um jogo e os elementos violentos começaram a ser mais controlados" (DUNNING, 2014, p. 172) - tendo adquirido grande importância nas sociedades de comunicação e informação. Sua análise pode contribuir para compreensão dos princípios e valores sobre os quais as sociedades capitalistas se organizam. Dito com outras palavras, capitalismo e sistema midiático se imbricam com a esfera esportiva contemporânea, de tal modo que "[...] esta simbiose vai além do simples relato dos fatos esportivos, chegando mesmo a interferir na configuração dos próprios jogos" (ALVAREZ; MARQUES, 2013, p. 5).

Entre as mais diversas modalidades esportivas, as Artes Marciais Mistas (MMA) caracterizamse "[...] pelo emprego de técnicas oriundas de diversas artes marciais e/ou esportes de combate, como capoeira, jiu-jitsu, muay thai, kickboxing, taekwondo, caratê, judô, wrestling, boxe, luta livre e kung fu" (GREESPAN, 2014, p.14). Esportes que têm origens em locais e momentos históricos variados, assumindo significados e funções sociais distintas. No entanto, ainda que tenhamos de adotar uma atitude cautelosa ao relacionar os esportes de combate modernos a seus antecedentes, não deixa de ser interessante notar que 0 evento mais popular nos Jogos Olímpicos da Antiguidade era o pankration, "[...] que pode ser descrito como uma fusão de elementos que costumamos associar ao boxe, 
à luta livre e ao judô. Era uma forma de luta sem regras, uma variante daquilo que hoje em dia chamamos de 'ultimate figthing', mas ainda mais violento e muito menos controlado (DUNNING, 2014, p. 167).

Hoje em dia, o UFC é o principal torneio de MMA do mundo, refletindo o contexto econômico e sociocultural no qual está inserido. Do ponto de vista econômico, o UFC origina-se numa época marcada pelo aumento global da concentração de poder dos grandes conglomerados e do crescimento de fluxo de informação, capitais e mercadorias. Do ponto de vista sociocultural, ele contribui para a disseminação de valores neoliberais, como a defesa de que 0 indivíduo seja 0 empreendedor de si mesmo, conforme retomaremos.

Inicialmente ligado aos combates de vale-tudo promovidos no Rio de Janeiro pelos irmãos Grace no início do século XX, o UFC surgiu em 1993, como um evento de lutas mistas transmitido ao vivo em pay-per-view no formato de show. Desde 0 início, já possuía uma estreita relação com a linguagem midiática, tanto que a forma octogonal de seus ringues foi inspirada no filme "Conan, o Bárbaro". Segundo Alvarez e Marques (2013, p.7), muito embora não se possa perder de vista 0 desejo de seu fundador Rorion Grace de disseminar pelo mundo o jiu-jitsu brasileiro, desenvolver lutas e torná-las esportivas, o UFC é "[...] muito mais a criação de um produto midiático do que uma disputa esportiva". Nas palavras de Grespan (2014, p.16): o UFC foi criado para ser um campeonato de lutas em formato de "show", um evento de consumo esportivo transmitido pela televisão através de PPV e sua promoção era realizada através da frase "there are no rules" ("não há regras").

De um campeonato de lutas cujo lema era "não há regras", o UFC precisou repensar seu formato para ser aceito como um esporte e não como um show de brutalidade, como era tratado pela mídia. Em 2001, o UFC foi "[...] vendido para os executivos do Station Casinos, Frank e Lorenzo Fertitta e 0 promotor de boxe Dana White, criadores da Zuffa, empresa controladora da patente do evento" (GRESPAN, 2014, p.17). A partir daí, aumentou 0 número de categorias de pesos e recebeu regras mais rígidas, passando a ser chamado de Artes Marciais Mistas e não mais Vale Tudo, como era conhecido até então.

\section{A origem e 0 crescimento do UFC estão} relacionados à sua ampla divulgação midiática na chamada "sociedade em rede" (CASTELLS, 1999), sendo difundido por meio de sites, blogs, televisão, canais de PPV, revistas, entre outros. A internet foi crucial para essa difusão e consequente aumento do número de espectadores. As redes sociais virtuais - com comentários de lutadores, treinadores e fãs - ajudaram a criar expectativas em relação às lutas e às(aos) próprias(os) atletas. A penetração midiática do UFC combina-se com 0 marketing esportivo, que contribui para divulgar os eventos e as(os) atletas, chamando a atenção dos patrocinadores. 
Neste contexto, o MMA tornou-se um produto global, passando a ser assistido e praticado não apenas por homens, mas também por mulheres. Grespan (2014), por exemplo, identificou que, desde os anos 1990, as mulheres lutam MMA e que esse número vem crescendo significativamente. De acordo com ele,

em dezembro de 2012, havia duas lutadoras oficialmente contratadas. Já em maio de 2014, havia 25 atletas oficialmente contratadas. Já em maio de 2014, havia 25 atletas. 0 primeiro ranking oficial do UFC da categoria das mulheres foi divulgado em 04 de março de 2013, a primeira mulher no ranking do peso por peso foi divulgada em 16 de dezembro de 2013 (GRESPAN, 2014, p. 26).

Levando em consideração 0 aumento do número de atletas mulheres nessa modalidade, cabe perguntar: "em que medida e como ela aparece como um espaço de disputas e resistências, apontando para uma representação na qual a mulher não se reduz ao modelo hegemônico de feminilidade?". Ainda: o modelo de normatização das atletas é uma reprodução de formas disciplinares de corpos e subjetividades que as colocam dentro de modelos preestabelecidos representados hegemonicamente pela sociedade de consumo? Há um padrão comportamental, estético e corporal predominante em um esporte espetacularizado, como o MMA?

Entre as diversas lutadoras dessa modalidade, Ronda é a que obteve maior visibilidade midiática. Muito embora as mulheres lutem MMA desde os anos 1990, elas só ganharam esse tipo de visibilidade em 2012, com a contratação da americana pelo UFC. Se antes o "todo-poderoso" da franquia, Dana White, manifestava-se contra a inserção das mulheres no evento, com a contratação de Ronda, passou a acolhê-las. Suas palavras são reveladoras: "“...] o MMA feminino só está no UFC por causa dela. Ela é a campeã e merece estar aqui'" (WHITE apud VICENTIM, 2013).

0 UFC segue os moldes da sociedade do espetáculo - na qual impera uma "[...] relação social mediatizada entre pessoas por imagens" (DEB0RD, 2007, §4) - e suas(es) atletas são verdadeiras celebridades, que, com frequência, fazem o papel de garotas(os)-propaganda de grandes empresas, representando estilos de vida associados à sociedade midiática e de consumo. No caso específico da Ronda, representando um modelo de feminilidade (ao menos no comercial da Reebok) próxima ao que Lipovetsky (2000) denomina de "terceira mulher", ou "mulher indeterminada". Modelo que diz respeito a um ideal de mulher que busca inventar a sua própria vida, sujeitandose apenas a si mesma. Isso não significa, no entanto, que este seja um modelo igualitário, pois mesmo que, atualmente, as mulheres tenham a possibilidade de independência econômica e não estejam mais, necessariamente, subordinadas ao homem, ainda assim, de maneira geral, tendem a ter salários inferiores, a não estar tão presentes na vida política e a continuar presas às tarefas domésticas, assumindo grande parte da 
responsabilidade pelas tarefas da casa e educação das(os) filhas(os).

Quando a mídia aborda a Ronda, não deixa de mencionar a sua aparência, conferindo-lhe grande importância. Grespan e Gellner (2014) afirmam que as reportagens e os comentários nos sites e blogs sobre o UFC se transformaram significativamente quando as mulheres entraram na franquia, sendo que a atleta americana foi um divisor de águas. De reportagens e comentários sobre o rendimento dos atletas, passou-se a tratar de temas como gênero, sexualidade e principalmente beleza.

Mas por que a beleza se tornou um tema recorrente na cobertura midiática de uma profissional exitosa? Afinal, estamos falando de uma lutadora de MMA e não de uma modelo ou atriz. A apologia midiática à beleza não deveria pertencer ao passado, contexto no qual a mulher se identificava apenas com universo privado? Segundo Lipovetsky (2000), a glorificação da beleza feminina liga-se ao "espírito moderno", caracterizado pelo individualismo, empreendedorismo, cultura da eficácia, controle técnico e autonomia. 0 tipo ideal descrito pelo autor como "terceira mulher" pertence a uma cultura industrial e midiática, na qual o consumo de imagens e produtos de beleza intensifica 0 culto da beleza feminina. Nas suas palavras: "[...] ao contrário de um dispositivo arcaico, o culto contemporâneo da beleza deve ser compreendido sob o signo moderno da não aceitação da fatalidade, da ascensão ao poder dos valores conquistadores de apropriação do mundo e de si" (LIPOVETSKY, 2000, p. 142).

A relação entre beleza e cultura individualista insere-se no conformismo de massa e na busca de um corpo que se torna objeto de um ininterrupto trabalho. Na perspectiva de Lipovetsky (2000), não há contradição entre o ideal de governo de si e o poder normalizador dos modelos estéticos disseminados pela cultura do consumo e comunicação de massa. 0 culto da beleza não se relaciona com a programação disciplinar dos corpos, mas com uma miríade de escolhas, decisões e participações dos que buscam estar a par com 0 ideal de beleza propagado pelo sistema midiático e industrial. Afinal, as grandes marcas da indústria cosmética e da moda propagam a beleza mercantil, que pressupõe um intenso gerenciamento de si.

Numa sociedade pós-tradicional, o culto das potencialidades individuais promove não apenas a autonomia como também a sensação de instabilidade devido à possibilidade de escolhas. Como não há mais referência à tradição (ou há muito menos), ao indivíduo cabe escolher reflexivamente entre as diversas narrativas que a ele se colocam. A relação que Lipovetsky (2000) estabelece entre beleza e aspiração feminina à autonomia e à vida profissional é mais inteligível quando explicada à luz do "eu como um projeto reflexivo", o que pressupõe uma autoconstrução ininterrupta (GIDDENS, 2002). Assim, quando 0 
indivíduo passa a ser responsável por si mesmo, 0 planejamento estratégico da vida assume especial importância. Ao deixar de ser identificada com um dom divino, a beleza torna-se um dever, e depende da conquista individual cada vez mais demandada por uma pletora de conselhos, informações e imagens ligadas a uma lógica de produção, consumo e comunicação midiática.

Dessa forma, a mídia - especialmente a dirigida às mulheres - possui um duplo papel de homogeneização das aparências e de valorização da individualidade e da personalidade. A beleza tornou-se sinônimo de êxito, bem-estar, equilíbrio e sucesso profissional. A sua importância relaciona-se à cultura da juventude e celebridades, na qual estamos imersos.

Em nossas sociedades, a beleza feminina já não é acusada de produzir o mal, é reproduzida como uma imagem de sonho para 0 consumo das massas: nossas deusas já não encontram seu modelo em Pandora, mas em Galatéia, com a diferença de que é preciso imaginar Pigmalião como empresário. A beleza equívoca e maldita foi substituída pela beleza mercantil, uma beleza funcionalizada a serviço de produção das marcas e do faturamento das indústrias do imaginário (LIPOVETSKY, 2000, p.182).

Isso significa que a valorização da beleza feminina corresponde à ampla inserção da mulher na esfera do trabalho? Lipovetsky (2000) não acredita nisso, pois 0 enaltecimento da beleza feminina parece apagar o desempenho profissional da mulher; aumentando, desta forma, a divisão entre as profissões ditas "masculinas" e "femininas".
Entre os inúmeros estereótipos que dominam nosso imaginário, ainda figura aquele no qual a beleza é algo frívolo, "coisa de mulher". Dessa forma, a beleza feminina se opõe à competência profissional. Nas palavras do referido autor (2000, p. 186): "em nossas sociedades, a condição de beleza pura constitui estruturalmente um problema porque fere 0 princípio segundo 0 qual apenas o que se faz pelo trabalho merece a consagração social".

Se o reconhecimento social passa pelo mérito individual, a "mitologia da autorrealização" (EHRENBERG, 2010) - na qual cada pessoa deve aprender a se autogovernar, buscando orientações para a sua existência em si própria - liga-se mais ao desempenho de si do que propriamente à sua aparência, que remete à frivolidade. Por isso, a beleza parece mais ligada às profissões do mundo da moda e ao enaltecimento das celebridades, especialmente quando exploradas pela publicidade. 0 ideal da auto superação vem atrelado à "sociedade do desempenho" (LIPOVETSKY, 2007), na qual a competição, a iniciativa e a auto expressão se tornam mais que um estilo de vida, constituindo-se num imperativo que as pessoas devem seguir sob pena de se sentirem excluídas do ideário social preconizado.

\section{Ideologia}

Uma vez apresentado o contexto de produção, transmissão e recepção do comercial \#PerfectNever, cabe agora apresentarmos 0 
conceito de ideologia utilizado. Neste trabalho, optamos por trabalhar com o conceito de ideologia desenvolvido por John B. Thompson em "Ideologia e Cultura Moderna" (2000). Em tal obra, 0 sociólogo de Cambridge defende que o referido conceito não deve ser entendido como um aspecto da vida social entre outros, independentemente de ele contribuir para a transformação ou para a preservação da ordem social. Ao contrário, Thompson entende que um fenômeno, para ser considerado ideológico, deve carregar consigo um criticismo implícito, sendo, portanto, condenável. Mas não por ele ser necessariamente enganador ou ilusório, mas por estar "a serviço da dominação", sendo que

podemos falar de "dominação" quando relações estabelecidas de poder são "sistematicamente assimétricas", isto é, quando grupos particulares de agentes possuem poder de uma maneira permanente, e em grau significativo, permanecendo inacessível a outros agentes, ou a grupos de agentes, independentemente da base sobre a qual tal exclusão é levada a efeito (THOMPSON, 2000, p. 80).

A partir dessa concepção de ideologia, uma forma simbólica (expressões linguísticas, gestos, ações etc.) será ideológica quando, em um contexto sócio histórico determinado, estabelecer e sustentar relações de dominação. Inversamente, será contestatória ou crítica da ideologia quando ajudar a minar essas relações. Desse modo, a interpretação do potencial ideológico ou contestatório de uma forma simbólica deve explicitar o vínculo entre os sentidos por ela mobilizados e as relações de dominação que esses sentidos mantêm ou subvertem. Deve, portanto, considerar os contextos sócio históricos específicos nos quais essa forma simbólica é produzida, transmitida e recebida. Por esta razão, de acordo com Thompson (2000), esse enfoque pode nos levar a interpretar uma forma simbólica como ideológica num contexto e como subversiva noutro. Mais ainda, pode levar-nos a interpretar uma mesma forma simbólica como ideológica sob certos aspectos e como contestatória sob outros.

\section{Metodologia}

Partindo da perspectiva de que "[...] a metodologia não tem status próprio, precisando ser definida em um contexto teórico-metodológico" (LUNA, 2006, p. 14), definimos a nossa a partir do referencial teórico do Thompson (2000), elegendo, assim, a chamada "hermenêutica de profundidade" (HP) para orientar nossas analises e interpretações. Afinal, conforme observam Jacques Aumont e Michel Marie (2004), uma vez que não existe um método universal para analisar filmes (incluindo os publicitários, acrescentamos nós), é preciso escolher aquele que melhor se ajuste ao objeto da pesquisa. Nas suas palavras: "[...] até certo ponto, não existem senão análises singulares, inteiramente adequadas no seu método, extensão e objeto, ao filme particular de que se ocupam" (AUMONT; MARIE, 2004, p. 15). E a HP é uma metodologia adequada para que possamos cumprir com o nosso propósito de realçar as maneiras como os sentidos do comercial selecionado servem para estabelecer 
e sustentar relações de dominação. Assim, seguindo sua estrutura tradicional, dividimos os procedimentos metodológicos em três etapas, "[...] que devem ser vistas não como estágios separados de um método sequencial, mas antes como dimensões analiticamente distintas de um processo interpretativo complexo" (THOMPSON, 2000, p. 365).

Na primeira etapa, cujos resultados foram apresentados no tópico 2 , analisamos o contexto sócio histórico de produção, transmissão e recepção do comercial \#PerfectNever, enfocando a história do MMA e a questão de gênero nesse esporte. Com isso, buscamos evitar o que Thompson (2000) denominou de "falácia do internalismo", que diz respeito à ideia (equivocada) de que é possível extrair as consequências de uma mensagem (e, portanto, seu caráter ideológico), única e exclusivamente, de seu conteúdo e estrutura.

Na segunda etapa, analisamos a organização interna do comercial em questão: suas características estruturais, seus padrões e relações. Além de ser um produto contextualizado (histórica, social e culturalmente), um comercial, como qualquer outra forma simbólica, também é um produto que, devido a suas características estruturais, tem a capacidade de dizer algo. Tratase de uma construção simbólica complexa, por meio da qual algo é expresso ou dito (THOMPSON, 2000). E é a análise dessa construção que buscamos empreender aqui.
Essa análise, todavia, envolve, necessariamente, transladar, que implica decisões e escolhas. "Existirão sempre alternativas viáveis às escolhas concretas feitas, e o que é deixado de fora é tão importante quanto o que está presente" (ROSE, 2008, p. 343). Assim, nunca haverá uma análise que consiga captar uma verdade única do texto. Não à toa, Jacques Aumont e Michel Marie (2004) argumentam que o processo analítico é interminável, uma vez que sempre sobrará algo de analisável. Afinal, analisar significa decompor os elementos pertinentes da obra e é sempre possível realizar novas decomposições.

Diante disso, é preciso fazer inúmeras escolhas no processo analítico. Escolhas que influenciarão 0 resultado da pesquisa, com vantagens e desvantagens, naturalmente. Sem dúvida, o primeiro passo de qualquer análise é a seleção do material, que não é, de modo algum, autoevidente (ROSE, 2008). Ao contrário, a transparência e a clareza na construção do corpus são alguns dos principais indicadores de confiabilidade e relevância em pesquisa qualitativa (GASKELL; BAUER, 2008). Nessa seleção, é preciso considerar o problema de pesquisa. Afinal, 0 material escolhido deve fornecer as informações necessárias para respondê-lo. A Ronda já fez, por exemplo, diversos comerciais. Sendo assim, qual deles tomar como objeto de análise? Depois de fazermos uma "varredura" nesses comerciais, escolhemos o da Reebok, uma vez que é aquele que trata mais diretamente do foco deste trabalho: relações de gênero e beleza feminina. Cabe aqui 
salientar que, conforme é praticamente consensual na literatura especializada, a melhor fonte será sempre a mais direta possível (LUNA, 2006).

Uma vez definido o material selecionado, é preciso considerar o tipo de leitura que se pretende fazer, na medida em que todo material oferece uma multiplicidade de leituras possíveis. Desta forma,

0 analista deve enfim decidir se considera 0 filme todo - ou impõe um certo tipo de escolha de objeto e uma certa intenção relativamente ampla - ou se, pelo contrário, irá tratar de um excerto ou aspecto. Em qualquer dos casos, a análise parcial deverá sempre inscrever-se na perspectiva de uma análise mais global, pelo menos potencialmente (AUMONT; MARIE, 2004, p. 41-42).

A leitura que realizamos do comercial \#PerfectNever buscou lançar um olhar atento tanto para suas dimensões visual e verbal quanto para as relações entre elas. Para realizar essa leitura, optamos, primeiramente, por assisti-lo repetida, cuidadosa e detalhadamente, buscando identificar as principais temáticas envolvidas. Em seguida, transcrevemos as falas enunciadas no comercial e fizemos sua tradução para 0 português (o texto original está em inglês). Essa transcrição teve como objetivo, única e exclusivamente, servir de apoio para uma análise mais abrangente. Afinal, o conteúdo de um filme nunca é independente da forma utilizada para exprimi-lo (AUMONT; MARIE, 2004).

Uma vez feita a transcrição, buscamos analisar a estrutura narrativa do comercial, entendendo por narrativa:
[...] um discurso que narra uma sequência de acontecimentos - ou, como dizemos comumente, que "conta uma história". A história geralmente contém uma constelação de personagens e uma sucessão de eventos, combinados de uma maneira que apresente certa orientação, ou "enredo" (THOMPSON, 2000, p. 373).

A fim de realizar essa análise, decompomos 0 comercial em "unidades narrativas" (AUMONT; MARIE, 2004), que foram, primeiramente, examinadas isoladamente e, depois, em conjunto. Aqui, cabe destacar que não seguimos à risca nenhum enfoque específico (Propp, Barthes, Greimas, Todorov, Genette etc.), mas, de uma maneira relativamente livre, buscamos entender como os ângulos da câmara, 0 ambiente das cenas, a caracterização das personagens, as falas, os silêncios, as ausências, as rupturas etc. contribuíram para a tessitura dos fios narrativos e, mais particularmente, para a construção do ponto de vista da protagonista, que, no caso, era também a narradora.

Na terceira etapa, buscamos, à luz do contexto analisado no tópico 2 , interpretar o caráter ideológico potencial dos sentidos mobilizados pela narrativa examinada, bem como seu caráter crítico potencial. Esse processo interpretativo foi construído sobre as análises anteriores, implicando um movimento novo de pensamento, que procedeu pela construção criativa de possíveis significados (THOMPSON, 2000). Não à toa, na perspectiva de Jacques Aumont e Michel Marie (2004), 0 processo interpretativo é, por assim dizer, o "motor imaginativo", "inventivo", da análise. 
Diante disto, esse processo é, necessariamente, arriscado, cheio de conflitos e aberto à discussão, mas isso não quer dizer que seja arbitrário, "delirante", uma "alucinação" (AUMONT; MARIE, 2004), como argumentam alguns analistas. Afinal, uma interpretação pode (e deve) ser provada, apresentando um conjunto de evidências, elucidações, razões e fundamentos que tornem razoáveis sua plausibilidade. Assim, a fim de provar as interpretações feitas aqui, buscamos mostrar, em primeiro lugar, como as características estruturais da narrativa sob análise constituem instâncias de estratégias de construção simbólica específicas. E, em segundo lugar, como que, no contexto de produção, transmissão e circulação dessa narrativa, essas estratégias podem estar ligadas a certos modos gerais de operação da ideologia (THOMPSON, 2000). Os resultados desta terceira e da segunda etapa foram sintetizados no tópico subsequente.

\section{Análise e interpretação do comercial \#PerfectNever}

\section{A Reebok é uma empresa transnacional de} produtos esportivos. Vendida recentemente para a Adidas por 3,8 bilhões de dólares, ela é a fornecedora exclusiva de roupas e equipamentos de treino para lutadores do UFC, que precisam usar os materiais da marca na semana que antecede 0 evento, não podendo utilizar patrocínios particulares. Além de ser a patrocinadora exclusiva do UFC, a Reebok patrocina individualmente uma série de lutadores e lutadoras, como a própria Ronda.

Vista até então como imbatível, a lutadora perdeu, conforme já antecipamos, o cinturão do peso galo feminino no fim de 2015, ao ser derrotada, de forma contundente, por Holly Holm. Foi neste contexto em que a peça publicitária da Reebok foi produzida e transmitida. De um modo geral, os discursos produzidos por peças ou publicitárias constituem uma narrativa que objetiva estabelecer vínculos emocionais entre a marca anunciada e o seu público-alvo, ainda que eles vão além disso. Afinal, contribuem para construir "estilos de vida", "visões de mundo", "padrões de beleza", "modelos de gêneros masculino e feminino", "sistemas de classificação" etc. (ROCHA, 1990).

No contexto esportivo, uma forma de criar vínculos emocionais é associando a marca anunciada à figura de atletas-celebridades, que são vinculadas(os) a ideais de iniciativa, competição, auto superação e obsessão pelo desempenho, como é o caso da peça sob análise. Intitulada \#PerfectNever, essa peça começa com a Ronda erguendo a cabeça e caminhando como se estivesse na passarela de um desfile de moda. Atrás dela, observa-se um céu dourado recortado por nuvens sensualmente roxas, que criam um cenário perfeito, contrastando com o título da peça, mas harmonizando com a sua beleza.

Além de ser uma atleta campeã mundial e internacionalmente reconhecida por suas 
técnicas e habilidades excepcionais, Ronda é considerada a musa do UFC. Seu corpo, todavia, é um pouco forte demais para o padrão de beleza feminino hegemônico, com características dos corpos típicos dos lutadores(as) de jiu-jitsu e MMA. Corpos-armadura (DIÓGENES, 2003), preparados para suportar os golpes dos(as) adversários(as). Corpos blindados, que não se curvam. Ronda possui, por exemplo, braços musculosos e orelhas inchadas. Orelhas "couveflor", no termo nativo. Orelhas típicas de alguém que já fraturou e esfarelou muitas vezes a cartilagem na lona do tatame.

\section{Essas características tidas como}

"masculinizantes", todavia, são inicialmente ocultadas no comercial. Os braços de Ronda são encobertos pelas mangas compridas de seu longo e sensual vestido preto e suas orelhas, pelo cabelo. Um cabelo comprido, brilhante e levemente ondulado, similar ao das estrelas dos comerciais de shampoo. Para reforçar sua "feminilidade", Ronda veste um largo decote em $\mathrm{V}$, que revela parte de seu busto e insinua seus seios. Além disso, a maquiagem de seu rosto o torna ainda mais bonito e sua pele dourada brilha, assim como 0 céu atrás dela.

Acompanhando a imagem, escuta-se ao fundo uma música instrumental, com violinos que vão se "enfurecendo" ao longo do comercial, aumentando a excitação da(0) espectador(a). Mas, de repente, tudo muda! 0 céu se apaga e escuta-se um estrondo. As câmaras por detrás do cenário-fantasia se revelam, assim como a ilusão de toda perfeição. Ronda, todavia, segue caminhando. De cabeça erguida, como se tivesse orgulho de quem realmente é.

Lentamente, ela vai desconstruindo a imagem anterior. A câmera foca seus belos olhos azuis, para, em seguida, mostrar seus cílios postiços sendo arrancados, assim como as mechas artificiais de seu cabelo, que vai sendo enrolado num coque, de quem não tem tempo a perder com frivolidades. Em seguida, a câmera fecha na sua mão, envolta por uma luva de treino. Com força, Ronda esfrega sua boca apagando o batom, que contornava e ressaltava a beleza de seus lábios. 0 cenário artificialmente colorido se desfaz e torna-se preto e branco. A musa sai de cena; a lutadora entra. Lutadora no duplo sentido da palavra: a lutadora atleta e a lutadora que enfrenta as adversidades com afinco. Que cai, mas levanta. Que perde, mas não desiste.

Ronda, então, enrola sua mão numa faixa, que é capturada num plano fechado. Faixa que amortece os impactos das lutas e dos treinos. Do seu dia-a-dia, que é mais doloroso do que glamoroso, conforme faz crer o comercial. Sua mão enfaixada opera, nesse momento, como uma metonímia - essa figura de linguagem tão utilizada na propaganda (THOMPSON, 2000). Afinal, toma 0 lugar da própria atleta, que é associada à figura da batalhadora, produzindo um sentido novo. Em última instância, a batalha do ringue simboliza uma batalha maior: a da própria vida. 
Em seguida, a câmera dá um close up em suas costas suadas, evocando a ideia de trabalho. Trabalho penoso e difícil. Ao mesmo tempo em que atua como uma metáfora de sua firmeza de vontade, 0 suor não deixa de revestir seu corpo com certa sensualidade. No momento subsequente, foca-se Ronda de frente, da cintura para cima, e a câmera revela seus braços "demasiadamente" musculosos, ombros largos e outras características corporais "masculinas". Ao mesmo tempo, a imagem vai fechando em seu rosto sério, franzido, até ela sentenciar, com olhos desafiadores e voz firme, que "se sente bem em não ser perfeita". 0 comercial mostra, então, uma imagem dela em ritmo alucinante socando um saco de treino, evocando novamente a ideia de sacrifício. Por último, exibe-se o logo da Reebok sobre uma tela preta, acompanhado dos dizeres "Be more human".

Importante notar que as imagens do comercial são acompanhadas por um texto narrado pela própria Ronda, como se ela fosse a autora daquilo que é dito. Como se fosse a sua própria voz que enfrentasse 0 ideal de perfeição imposto a ela e a todo atleta de elite. 0 conteúdo do texto é lapidar: "Here's the thing about being perfect. Perfect never gets truly tested. Perfect never gets to silence its critics. Perfect never gets a shot at redemption. So yeah, I'm fine with not being perfect. ${ }^{3 "}$

Por um lado, a mensagem do comercial subverte 0 discurso hegemônico sobre as estrelas do esporte mundial, que são metaforicamente associadas à ideia de perfeição ${ }^{4}$, e desafia os padrões impostos para as mulheres. Afinal, sugere-se que Ronda não se importa em não ter um cabelo impecável e aparecer suada e sem maquiagem diante das câmeras. Seu desprezo pela perfeição é também um desprezo pelo modelo histórico de "mulher enaltecida" (LIPOVETSKY, 2000), uma vez que não aceita se subordinar à imagem de "musa inspiradora". Imagem que, em última instância, desloca a atenção de suas qualidades como atleta para seus atributos estéticos. Ao contrário, Ronda parece se orgulhar de ser uma atleta e não sentir vergonha de ser derrotada. Afinal, só assim é possível calar seus críticos e ter uma chance de redenção, como ela mesma diz no comercial.

\section{Considerações finais}

Seguindo essa linha de raciocínio, pode-se afirmar que, do ponto de vista das relações de gênero, a mensagem evocada pela peça publicitária é potencialmente subversiva. Afinal, coloca em xeque o modelo de "mulher enaltecida" e exalta

"Seja mais humano", tradução nossa.

"Aqui está um fato sobre ser perfeito. Perfeito nunca é verdadeiramente testado. Perfeito nunca pode calar os seus críticos. Perfeito não tem uma chance de redenção. Então, sim. Eu me sinto bem por não ser perfeita", tradução nossa.

Até mesmo porque seria praticamente impossível manter a imagem da Ronda de "rainha do MMA" depois da derrota acachapante para Holly Holm. 
o modelo de "mulher indeterminada", capaz de criar a própria história (LIPOVETSKY, 2000).

Ao fazer isto, contribui, em certo sentido, para desnaturalizar as relações de gênero, sugerindo que a vida das mulheres não é o resultado inevitável de suas características naturais. Ao contrário, as formas de ser e vivenciar a feminilidade são (ou podem ser), como nos mostra Ronda, estabelecidas pelas próprias mulheres, desestabilizando preconceitos de gênero travestidos de verdades biológicas.

Por outro lado, é possível inferir que o potencial subversivo do comercial possui limitações. Afinal, ainda que o conteúdo de sua narrativa seja, em alguma medida, provocador e contestador da ordem social vigente, colocando em xeque o papel (subalterno) da mulher na sociedade atual, isso é feito de modo rápido, efêmero e superficial, sem procurar fornecer pistas das condições que permitem a (re) produção dessa mesma ordem. Em outras palavras, ele não permite o exame lógico dessas condições.

Vislumbrar suas causas. Consequentemente, é possível indagarmos até que ponto é realmente capaz de se transformar num desafio às estruturas de dominação de gênero, indicando ações concretas que possam transformá-las.

Também é possível inferir que a mensagem evocada pela peça publicitária é capaz de reforçar relações de dominação de classe, uma vez que esse questionamento é feito por meio do consumo. Afinal, toda propaganda busca fazer com que 0 seu público-alvo desempenhe eficazmente o papel de consumidor(a), não precisando da explícita orquestração de ninguém. Com isto, ainda que um comercial tenha uma dimensão crítica, ele tende a pressupor a naturalização dos valores e das crenças que servem ao sistema capitalista, que, como sabemos desde Marx, é mantido por meio da dominação e exploração de classe.

É preciso destacar, no entanto, que isto não quer dizer, necessariamente, que 0 receptor das mensagens publicitárias irá aceitar passivamente 0 papel social de consumidor que lhe foi destinado. Há fortes evidências de que, nas sociedades industriais modernas, existe um grau significativo de dissenso e não satisfação. A mensagem, como nos lembra Thompson (2000), é sempre decodificada e apropriada de forma ativa, podendo ser lida de forma crítica.

Diante disto, concluímos este trabalho observando que, para entendermos os significados da mensagem do comercial \#PerfectNever para 0 seu público-alvo e as formas como ele a recebe e se apropria dela no curso do seu cotidiano, seria necessário o desenvolvimento de uma análise da vida desse público e das maneiras como ela é transformada pelo referido comercial. Análise que buscaremos realizar em trabalhos futuros.

\section{Referências}

ALVAREZ, Fábio; MARQUES, José Carlos. Da marginalidade ao mainstream: reflexões sobre o MMA (Artes Marciais Mistas) e as sociedades capitalistas contemporâneas. Revista da Associação dos 
Programas de Pós-Graduação E-compós, Brasília, v.16, n.3, set./dez., 2013. Disponível em: http://www. compos.org.br/seer/index.php/e-compos/article/ viewFile/965/713. Acesso em: 20 de mar. 2015.

AUMONT, Jacques; MARIE, Michel. A análise do filme. 3 ed. Lisboa : Edições Texto \& Grafia, 2004.

CASTELLS, Manoel. A sociedade em rede: a era da informação: economia, sociedade e cultura. São Paulo, Paz e Terra, 1999.

DEBORD, G. A sociedade do espetáculo. Rio de Janeiro: Contraponto, 2007.

DIÓGENES, Glória. Itinerários de corpos juvenis: 0 tatame, o jogo e o baile. São Paulo: Annablume, 2003.

DUNNING, Eric. Sociologia do esporte e os processos civilizatórios. São Paulo: Annablume, 2014.

GASKELL, George; BAUER, Martin W. Para uma prestação de contas públicas: além da amostra, da fidedignidade e da validade. In: BAUER, Martin W.; GASKELL, George (Org.). Pesquisa qualitativa com texto, imagem e som: um manual prático. ( $7^{\mathrm{a}}$ ed.) Petrópolis: Vozes, 2008, p. 470-490.

GIDDENS, Anthony. Modernidade e Identidade. Rio de Janeiro: Zahar, 2002.

\section{GRESPAN, Carla Lisbôa. Mulheres no 0ctógono:}

performatividades de corpos e de sexualidades. 2014. 119 f. Dissertação (Mestrado) - Escola de Educação Física, Programa de Pós-Graduação em Ciências do Movimento Humano, UFRS, Porto Alegre, 2014.

GRESPAN, Carla; GOELLNER, Silvana. Mulheres no Octógono: esporte e atravessamento de fronteiras. In: VII Congresso Sulbrasileiro de Ciências do Esporte, 2014, Paraná. Anais do VII Congresso Sulbrasileiro de Ciências do Esporte. Secretarias do Colégio Brasileiro de Ciências do Esporte. Matinhos, Paraná, 25 a 27 de setembro 2014, p.1-14. Disponível em: http:// congressos.cbce.org.br/index.php/7csbce/2014/paper/ viewFile/5940/3236. Acesso em: 02 mar. 2015.
EHRENBERG, Alain. 0 culto da performance: da aventura empreendedora à depressão nervosa. São Paulo: Ideias e Letras, 2010.

LIPOVETSKY, Gilles. A terceira mulher: a permanência e a revolução do feminino. São Paulo: Companhia das Letras, 2000.

\section{A felicidade paradoxal:}

ensaios sobre sociedade e hiperconsumo. São Paulo: Companhia das Letras, 2007.

LUNA, Sérgio. Planejamento de pesquisa: uma introdução. São Paulo: Educa, 2006.

ROCHA. Everardo. Magia e capitalismo: um estudo antropológico da publicidade. São Paulo: Brasiliense, 1990.

ROSE, Diana. Análise de imagens em movimento. In: BAUER, Martin W.; GASKELL, George (Org.). Pesquisa qualitativa com texto, imagem e som: um manual prático. (7ª ed.) Petrópolis: Vozes, 2008, p. 343-364.

THOMPSON, John B. Ideologia e cultura moderna: teoria social e crítica na era dos meios de comunicação de massa (4a ed.). Petrópolis: Vozes, 2000.

VICENTIM, Joice. Ronda Rousey: conheça a história desse furacão que mudou o destino do MMA feminino. 5 fev. 2013. Disponível em: http:// mmapremium.com.br/16783/ronda-rousey-conheca-ahistoria-desse-furacao-que-mudou-o-destino-do-mmafeminino/. Acesso em: $12 \mathrm{dez} .2015$.

\section{Sites consultados}

NETO, João Zaneta. Os segredos do marketing do UFC. 03 de set. 2011. Disponível em: http://mmabrasil. com.br/os-segredos-do-marketing-do-ufc. Acesso em 02 fev. 2016. 
Sport, gender and ideology: (de) constructing Ronda Rousey in the advertising campaign \#PerfectNever

\section{Abstract}

This paper seeks to answer the following questions: how women athletes from Ultimate Fighting Championship (UFC) are symbolically constructed by advertising campaigns? To what extent and how these constructions are interwoven with relations of gender domination in a sport traditionally considered masculine? Taking these questions as a starting point, we analysed and interpreted the ideological and contestatory potential of the meanings mobilized by the advertising campaign \#PerfectNever, acted by the ex UFC champion Ronda Rousey. Therefore, we adopted the methodology of depth hermeneutics, developed by Thompson. Among other things, we concluded that, from the point of view of gender relations, the campaign is potentially subversive and, from the point of view of class relations, it is potentially ideological.

\section{Keywords}

Sport. Gender. Ideology. Advertising.

\section{Deporte, género e ideología:} la (de)construcción de Ronda Rousey en el comercial \#PerfectNever

\section{Resumen}

Este trabajo pretende responder las preguntas: ¿cómo las atletas de Ultimate Fighting

Championship (UFC) son construidas

simbólicamente por campañas de publicidad?

¿En qué medida y cómo estas construcciones se entrecruzan con relaciones de dominación de género en un deporte tradicionalmente considerado masculino? Analizamos e interpretamos el potencial ideológico y contestatario de los sentidos movilizados por el comercial \#PerfectNever, protagonizado por la ex campean de UFC Ronda Rousey. Para esto, adoptamos la metodología de le hermenéutica de profundidad, de Thompson. Entre otras cosas, concluimos que, desde el punto de vista de las relaciones de género, el comercial es potencialmente subversivo y, desde el punto de vista de las relaciones de clase, potencialmente ideológico.

\section{Palabras-clave}

Deporte. Género. Ideología. Publicidad. 


\section{Expediente}

A revista E-Compós é a publicação científica em formato eletrônico da Associação Nacional dos Programas de Pós-Graduação em Comunicação (Compós). Lançada em 2004, tem como principal finalidade difundir a produção acadêmica de pesquisadores da área de Comunicação, inseridos em instituições do Brasil e do exterior.

\section{E-COMPÓS I www.e-compos.org.br I E-ISSN 1808-2599}

Revista da Associação Nacional dos Programas de Pós-Graduação em Comunicação. Brasília, v.20, n.3, set./dez. 2017. A identificação das edições, a partir de 2008 , passa a ser volume anual com três números. Indexada por Latindex I www.latindex.unam.mx

\section{CONSELHO EDITORIAL}

Ada Cristina Machado Silveira, Universidade Federal de Santa Maria, Brasil Alda Cristina Silva da Costa, Universidade Federal do Pará, Brasil Alfredo Luiz Paes de Oliveira Suppia, Universidade Estadual de Campinas, Brasil Ana Regina Barros Rego Leal, Universidade Federal do Piauí, Brasil Ana Carolina Rocha Pessôa Temer, Universidade Federal de Goiás, Brasil André Luiz Martins Lemos, Universidade Federal da Bahia, Brasil Angela Cristina Salgueiro Marques, Universidade Federal de Minas Gerais, Brasil Ângela Freire Prysthon, Universidade Federal de Pernambuco, Brasil Antonio Carlos Hohlfeldt, Pontifícia Universidade Católica do Rio Grande do Sul, Brasil Arthur Ituassu, Pontifícia Universidade Católica do Rio de Janeiro, Brasil

Bruno Campanella, Universidade Federal Fluminense, Brasil

Cláudio Novaes Pinto Coelho, Faculdade Cásper Líbero, Brasil Cárlida Emerim, Universidade Federal de Santa Catarina, Brasil Carlos Eduardo Franciscato, Universidade Federal de Sergipe, Brasil Danilo Rothberg, Universidade Estadual Paulista, Brasil Denise Tavares da Silva, Universidade Federal Fluminense, Brasil Diógenes Lycarião, Universidade Federal do Ceará, Brasil Eduardo Vicente, Universidade de São Paulo, Brasil Eliza Bachega Casadei, Escola Superior de Propaganda e Marketing - SP, Brasil Eneus Trindade, Universidade de São Paulo, Brasil

Erick Felinto de Oliveira, Universidade do Estado do Rio de Janeiro, Brasil Erly Vieira Júnior, Universidade Federal do Espírito Santo, Brasil Francisco de Assis, FIAM-FAAM Centro Universitário, Brasi

Francisco Elinaldo Teixeira, Universidade Estadual de Campinas, Brasil Francisco Gilson R. Pôrto Jr., Universidade Federal do Tocantins, Brasil Frederico de Mello Brandão Tavares, Universidade Federal de Ouro Preto, Brasil Gabriela Reinaldo, Universidade Federal do Ceará, Brasil Gilson Vieira Monteiro, Universidade Federal do Amazonas, Brasil Gustavo Daudt Fischer, Universidade do Vale do Rio dos Sinos, Brasil Itania Maria Mota Gomes, Universidade Federal da Bahia, Brasil Jiani Adriana Bonin, Universidade do Vale do Rio dos Sinos, Brasil José Afonso da Silva Junior, Universidade Federal de Pernambuco, Brasil José Luiz Aidar Prado, Pontifícia Universidade Católica de São Paulo, Brasi Josette Maria Monzani, Universidade Federal de São Carlos, Brasi Juçara Gorski Brittes, Universidade Federal de Ouro Preto, Brasil
Juliana Freire Gutmann, Universidade Federal da Bahia, Brasil Laura Loguercio Cánepa, Universidade Anhembi Morumbi, Brasil Leonel Azevedo de Aguiar, Pontifícia Universidade Católica do Rio de Janeiro, Brasil Letícia Cantarela Matheus, Universidade do Estado do Rio de Janeiro, Brasil Luciana Coutinho Souza, Universidade de Sorocaba, Brasil Maria Ataide Malcher, Universidade Federal do Pará, Brasil Maria Elisabete Antonioli, Escola Superior de Propaganda e Marketing - SP, Brasil Maria das Graças Pinto Coelho, Universidade Federal do Rio Grande do Norte, Brasil Marialva Carlos Barbosa, Universidade Federal do Rio de Janeiro, Brasil Marcel Vieira Barreto Silva, Universidade Federal da Paraíba, Brasil Marcia Tondato, Escola Superior de Propaganda e Marketing, Brasil Marli Santos, Universidade Metodista de São Paulo, Brasil

Márcio Souza Gonçalves, Universidade do Estado do Rio de Janeiro, Brasil Mauricio Mario Monteiro, Universidade Anhembi Morumbi, Brasil Mayka Castellano, Universidade Federal Fluminense, Brasil

Mozahir Salomão Bruck, Pontifícia Universidade Católica de Minas Gerais, Brasil Nisia Martins Rosario, Universidade Federal do Rio Grande do Sul, Brasil Paolo Demuru, Universidade Paulista, Brasil

Paula Melani Rocha, Universidade Estadual de Ponta Grossa, Brasil Potiguara Mendes Silveira Jr, Universidade Federal de Juiz de Fora, Brasil Priscila Ferreira Perazzo, Universidade Municipal de São Caetano do Sul, Brasil Rafael Cardoso Sampaio, Universidade Federal do Paraná, Brasil Rafael Tassi Teixeira, Universidade Tuiuti do Paraná, Brasil Regiane Lucas Garcês, Universidade Federal de Minas Gerais, Brasil Regiane Regina Ribeiro, Universidade Federal do Paraná, Brasil Renata Pitombo Cidreira, Universidade Federal do Recôncavo da Bahia, Brasil Renato Essenfelder, Escola Superior de Propaganda e Marketing, Brasil Roberto Elísio dos Santos, Universidade Municipal de São Caetano do Sul, Brasil Rodolfo Rorato Londero, Universidade Estadual de Londrina, Brasil Roseli Figaro, Universidade de São Paulo, Brasil

Simone Maria Andrade Pereira de Sá, Universidade Federal Fluminense, Brasil Sofia Cavalcanti Zanforlin, Universidade Católica de Brasília, Brasil Sônia Caldas Pessoa, Universidade Federal de Minas Gerais, Brasil Tatiana Oliveira Siciliano, Pontifícia Universidade Católica do Rio de Janeiro, Brasil Thaïs de Mendonça Jorge, Universidade de Brasília, Brasil

Valquiria Michela John, Universidade Federal do Paraná, Brasil

\section{CONSELHO CIENTÍFICO}

Cristiane Freitas Gutfreind, Pontifícia Universidade Católica do Rio Grande do Sul, Brasil | Eduardo Antônio de Jesus, Universidade Federal de Minhas Gerais, Brasil I Eduardo Morettin, Universidade de São Paulo, Brasil I Irene de Araújo Machado, Universidade de São Paulo, Brasil I Miriam de Souza Rossini, Universidade Federal do Rio Grande do Sul, Brasil

\section{COMISSÃO EDITORIAL}

Eduardo Antonio de Jesus, Universidade Federal de Minas Gerais, Brasil I Igor Pinto Sacramento, Universidade Federal do Rio de Janeiro, Brasil I Kelly Cristina de Souza Prudencio, Universidade Federal do Paraná, Brasil I Osmar Gonçalves dos Reis Filho, Universidade Federal do Ceará, Brasil I Rafael Grohmann, FIAMFAAM - Centro Universitário, Brasil (editor associado)

\section{CONSULTORES AD HOC}

Afonso de Albuquerque, Universidade Federal Fluminense, Brasil I Francisco Rüdiger, Pontifícia Universidade Católica do Rio Grande do Sul, Brasil I Gislene da Silva, Universidade Federal de Santa Cataria, Brasil I Luiz Cláudio Martino Universidade de Brasília, Brasil I Magali Nascimento Cunha, Universidade Metodista de São Paulo, Brasil I Márcia Franz Amaral, Universidade Federal de Santa Maria, Brasil I Tania Marcia Cezar Hoff, Escola Superior de Propaganda e Marketing, Brasil I Raquel Paiva, Universidade Federal do Rio de Janeiro, Brasil

\section{EQUIPE TÉCNICA}

ASSISTENTE EDITORIAL Márcio Zanetti Negrini I REVISÃO DE TEXTOS Melina Santos I EDITORAÇÃO ELETRÔNICA Roka Estúdio
COMPÓS I www.compos.org.br

Associação Nacional dos Programas de Pós-Graduação em Comunicação

Presidente

Marco Roxo

Programa de Pós-Graduação em Comunicação - UFF marcos-roxo@uol.com.br

Vice-Presidente

Isaltina Gomes

Programa de Pós-Graduação em Comunicação - UFPE isaltina@gmail.com

Secretária-Geral

Gisela Castro

Programa de Pós-Graduação em Comunicação

e Práticas de Consumo - ESPM

castro.gisela@gmail.com

CONTATO I revistaecompos@gmail.com 